\title{
Vaarao Amenhotep IV (Ehnatoni) riigivalitsemisviisi võimalikust eripärast $^{1}$
}

\author{
Tarmo Kulmar
}

\begin{abstract}
Teesid: Artiklis uuritakse, mil moel on Vana-Egiptuse Uue riigi vaarao Amenhotep IV (Ehnatoni) religioonireform seotud muutustega riigivalitsemissüsteemis. Analüüsist, mis tugineb ajaloolisele andmestikule ja lähtub autori nn varatotalitaarse riigi kontseptsiooni skeemist, ilmneb, et Ehnatoni valitsemisviis vastab täielikult või peaaegu täielikult varatotalitaarse riigi tunnustele ainult ajaloolis-poliitiliste põhjuste ja ideoloogia faktorite osas, osaliselt administratsiooni ja õiguskorra osas, vaid vähesel määral võib leida varatotalitaarsuse tunnuseid majanduse ja sotsiaalelu vallas. Välispoliitika faktor ei näita Ehnatoni valitsemisviisi puhul varatotalitaarsuse tunnuseid. Üsna suure tõenäosusega saab järeldada, et vaarao Amenhotep IV (Ehnaton) oli liikumas varatotalitaarse riigivalitsemisviisi poole ja on võimalik, et Ehnatoni eksperiment oli üks varaseimaid teadaolevaid varatotalitaarse riigi loomise katseid ajaloos.
\end{abstract}

Märksõnad: Amenhotep IV (Ehnaton), ideoloogia, monoteism, religioon, riigivõim, Vana-Egiptus, varajane totalitarism

\section{Sissejuhatuseks}

Järgnevalt käsitletakse Vana-Egiptuse nn imperiaalse perioodi ehk Uue riigi $(1570-1070 \mathrm{eKr})^{2}$ ühe väljapaistvaima valitseja Amenhotep IV (1350-1334 eKr $)^{3}$ revolutsioonilisi samme religiooni vallas, keskendudes sellele, kuidas kajastus usureform tema riigivalitsemistegevuses. Esmalt antakse põgus ülevaade Egiptuse Uue riigi XVIII dünastia (1570-1293 eKr) ajaks välja kujunenud sotsiaalpoliitilisest struktuurist, seejärel vaadeldakse tema tähtsaimaid sisepoliitilisi ettevõtmisi. Lõpuks antakse tema tegevusele hinnang lähtuvalt nn varatotalitaarse riigi kontseptsioonist. Siinkirjutaja eesmärk on uurida, kas ja mil määral on Amenhotep IV (Ehnatoni) valitsemisviisi puhul võimalik rääkida varatotalitaarsest riigist. 
Antud perioodi kirjalikeks allikateks on põhiliselt Amarna haua- ja raidkirjad (sh hümnid Atonile) ning Amarna kirjavahetus (vt nt Murnane 1995; Moran 1997). Olgu rõhutatud asjaolu, et siinkirjutaja ei ole egüptoloog ja tugineb tunnustatud uurijate töödele, kasutades Vana-Egiptuse ainest vaid oma eelnimetatud kontseptsiooni näitlikustamiseks.

\section{Uus riik, Amenhotep IV (Ehnaton) ja tema reformid}

Vaarao Amenhotep IV troonile asumise ajaks oli Egiptus muutunud tollase maailma vägevaimaks riigiks, eriti tänu Amenhotep IV võimekate eelkäijate Thutmosis III ja Amenhotep III edukatest sõjakäikudest, kasulikest poliitilistest sobimustest ja oskuslikust haldamisest tulenenud militaarsele tugevusele, seesmisele stabiilsusele ja majanduslikule õitsengule. Laialt tunnustatud seisukoha järgi (nt Grimal 1992; vt ka Doherty 2004: 33-44) olid riiklust ühendavateks faktoriteks järgmised asjaolud:

* Vaarao kui sisuliselt piiramatu võimuga valitseja, kes oli samaaegselt poliitiline, sõjaline ja usuline juht, vahemees inimeste ja jumalate vahel, kummardatud kui elav jumal maa peal.

* Lisaks noomide kaitsejumalatele oli välja kujunenud väga austatud plejaad üld-Egiptuse jumalaid. Erilisel kohal olid Amon-Ra (Amon Teeba kaitsejumalana oli saanud peajumalaks ja sulanud kokku päikesejumala Raga), viljakusjumalad Osiris ja Isis ning maailmakorra kehastus Maat.

* Sõjaväkke, mis koosnes jalaväest, ratsaväest, sõjavankritest ja laevastikust, kuulusid egiptlastest kutselised ja sõja korral ka sunniviisiliselt värvatud sõjamehed, samuti võõramaised palgasõdurid. Korda kindlustasid tähtsamatesse keskustesse paigutatud garnisonid.

* Mõjukas preesterkond, eriti ülempreestrid, kellele olid delegeeritud vaarao põhilised usulised kohustused. Tähtsaim neist oli Teeba Amon-Ra templi ülempreester, kelle autoriteet eriti Uue riigi lõpuajal kippus ohustama vaarao võimu. Templid olid olulised majandus-, haridus- ja kultuurikeskused.

* Ametnikkond, kes osaliselt kattus madalama preesterkonnaga, koosnes kirjutajatest, arvepidajatest ja ülevaatajatest. Sugulusvahekordade, kinnise informatsiooni valdamise ja kõrge õukondliku positsiooni tõttu oli suur osa neid korrumpeerunud (kui kasutada nüüdisaja mõisteid).

* Kesksed riitused - looduse taassünnile ja perioodilisele elluärkamisele pühendatud Osirise riitus, samuti surnu- ja teispoolsusekultus, mis tähendas surmaks valmistumist aegsasti eluajal, sh võimalusel hauakambri 
ehitamist ning vahendite kogumist mumifitseerimiseks ja rohketeks hauapanusteks, et tagada igavene elu.

Näeme, et poliitiliste, majanduslike ja sotsiaalsete faktorite kõrval olid vähemalt sama olulised religioossed ja - tänapäevaselt väljendatult - ideoloogilised faktorid.

Vaarao sünninimi oli Amen-hotep (Amon on rahul). Viiendal valitsemisaastal võttis ta uue sünninime Ehn-aton (Meelepärane Atonile). Ometi oli tal kogu valitsusaja jooksul üks ja sama valitseja- ehk trooninimi: Nefer-heperura-ra (Kaunid on Ra taastekked) (Clayton 2001: 120). Ta oli Amenhotep III ja selle peanaise (Suure Kuningliku Abikaasa) Tii teine poeg. Arvatavasti kutsuti ta troonile pärast vanema venna surma isa kaasvalitsejana juba selle viimastel eluaastatel, nagu see Egiptuses kombeks oli. Ta lasi end kroonida Lõuna-Egiptuses Hermonthises päikesejumala Ra-Harahte templis (Jacq 2000: 46), ta abiellus oma ema (kuninganna Tii) venna, minister Eje tütre (st onutütre) Nofretetega (Jacq 2000: 120-121; vt ka David 2005: 206) keda Tell el-Amarna varemetest leitud büstide põhjal võib pidada üheks ilusaimaks naiseks ajaloos; olgu mainitud, et Nofretete nimi tähendas 'Kaunitar on tagasi tulnud' (Stadnikov 1998a: 320). Seega esimesed 4 või 5 aastat trooniloleku umbes 17 aastast oli Amenhotep IV valitsusaeg täiesti tavapärane. Revolutsioonilised sammud jäävad järgmisse aastakümnesse.

Kuigi algul laskis vaarao kujutada end tavakohaselt koos peajumala Amoniga, hakkas ta üha enam eelistama päikeseketast Atonit. Seda päikesejumala Ra ilmumisvormi olid austanud juba tema eelkäijad Thutmosis IV ja Amenhotep III. Amenhotep IV ehitas Teebas Karnakki Atoni templi ja andis Atoni kultusele uue sisu. Muutnud oma sünninime Ehnatoniks, alustas ta järjekindlat reformeerimist, kasutades üha enam ka repressiivseid võimuvahendeid.

Esmase sammuna eemaldas Amenhotep IV Teebast Amoni templi ülempreestri, saates ta ekspeditsioonijuhina idapoolsesse kõrbesse, sest uue religioosse liikumise peavaenlaseks oli kindlasti vana peajumala Amoni preesterkond. Ta laskis Karnakki ehitada Atoni templi, kus erakordselt ilmekalt avaldub uus kunstistiil, mille järgi kujutati vaaraod naturalistlikult, koos tema kehaliste iseärasustega, mis oli seninägematu. Kunstiliselt laskis ta Atonit nüüd kujutada päikesekettana, mille ainsateks antropomorfseteks tunnusteks on inimkäed päikesekiirte otstes. Teoloogiliselt tähendas see universaalse maailmareligiooni ideed, mille kohaselt oli Aton jumal, peale kelle ei ole kedagi teist (Stadnikov 1998a: 317). Etniliselt ilmneb see samuti ennekuulmatus idees, et Atoni silmis on kõik rahvad ja keeled (vt Assmann 1975: 218-219), nii egiptlased kui ka võõramaalased, samaväärsed (vt Hornung 1978: 99), sest nad kõik on Atoni lapsed. Võib siiski olla üsna kindel, et Ehnaton ei jutlustanud kõikide 
inimeste võrdsust, mis väljendub kaudselt selles, et esimesel uuendusperioodil ei kiusatud taga seniseid jumalaid ega nende kummardajaid, kes moodustasid Egiptuse rahvastiku rõhuva enamuse. Ehnaton eemaldas võimu juurest ka suure osa vanast ametkonnast, kutsudes oma õukonda ametnikke, ohvitsere ja preestreid, kes ei pärinenud ülikkonnast, või olid koguni võõramaalased. Vaarao kasvatas endale liitlasi.

Olles ette valmistanud ustava toetajaskonna, alustas Ehnaton oma ettevõtmise keskset faasi. Ka siin võib eristada mitut etappi.

Esiteks hülgas ta mõlemad pealinnad, nii uue Teeba kui ka vana Memfise, ja laskis rajada nende vahele, umbes poolele teele mõlemast, uue kuningliku pealinna Ahet-Atoni (Atoni silmapiir). See oli üksildane paik, millel ei olnud kokkupuuteid teiste jumalate kultustega. Praegu kutsutakse seda kohta Tell el-Amarnaks. Arvatavasti oli Ehnaton ise olnud linna väga eripärase planeeringu autoreid. Riigi majanduspoliitika tuli ümber struktureerida, sest AhetAtoni ehitustöödeks tuli sinna sunniviisiliselt suunata suurel hulgal lihttööjõudu ja oskustöölisi, samuti oluline osa laekuvast andamist, et muretseda ehitusmaterjale, toiduaineid ja muud tarvilikku (Jacq 2000: 62-65). Tohutu mahuga ehitustööd kandsid kiire tempo tõttu suure kiirustamise jälgi (Jacq 2000: 74). Uus õukond eesotsas Ehnatoniga kolis pooleliolevasse linna juba järgmisel aastal. Pärast Ehnatoni surma jäeti Ahet-Aton maha (vt Ahet-Atoni kohta koos viidatud kirjandusega David 2005: 209-214). Ka see oli enneolematu Egiptuse senises ajaloos, mille traditsiooni põhitunnusteks oli iidsus ja järjekestvus.

Teiseks, et nähtavasti tugevnes Amoni preestrite vastuseis ja kindlasti kasvas kogu maal Atoni-vastane kihutustöö, asus Ehnaton vastukaaluks hiljemalt oma viiendal valitsemisaastal hävitama Amoni kultust. Amoni nime püüti kõikjalt raidkirjadest maha kraapida, et see vajuks unustusse. Vaenamine laienes ka teistele jumalatele. Ehnaton kuulutas, et Aton ei salli enam ühegi teise jumala olemasolu, saates kõigi teiste jumalate preestrid laiali ja ja suunates nende templite sissetulekud Atoni toetuseks (David 2005: 209). Korralduse täitmist jälgis vaarao julgeolekuteenistus ning vanale usundile truuksjäänuid represseeriti (Jacq 2000: 150jj).

Ühe jumala kuulutamine vääraks ja tema kultuse käsukorras hävitamine oli ennekuulmatu tegu mitte ainult Egiptuses, vaid tõenäoliselt kogu inimkonna senises ajaloos.

Samal ajal arendas Ehnaton nii teoloogias kui ka riituses egiptlastele võórast Atoni kui ainujumala kultust. Varasema usundi rikas mütoloogia jäi täiesti tahaplaanile, asendudes Atoni hümnidega, millest osa oli loonud tõenäoliselt Ehnaton ise (vt nt Lichtheim 1976: 96-99; David 2005: 215-217). Atoni templites polnud pühamuid ega kultusekujusid. Riituse põhiline iseärasus oli asja- 
olu, et Atoni ülempreestriks oli Ehnaton ise, kuningas oli jumala ainus maine esindaja. Erinevalt varasematest riitustest, mida toimetati templites, kummardati kuningat jumalana tema palees (vt Shafer 1997: 180-183). Tähtis koht oli mõjurikastel avalikel protsessioonidel (Jacq 2000: 146jj, 178). Tekkis koguni valitseja ja tema pereliikmete kui nn kodujumalate kultus, mis jällegi oli täiesti uus nähtus Egiptuse religioonis (vt Morenz 1984: 155; Assmann 1984: 251-253). Sisuliselt olid Aton ja Ehnaton saanud üheks. Niisiis on tegemist kuninga isiku erakordse - lausa totaalse absolutiseerimistaotlusega (vt ka Stadnikov 1998: 43), mis hõlmas nii sekulaarset kui ka religioosset tasandit.

Niivõrd radikaalsed sammud tõid kaasa rea tagasilööke.

Uude pealinna siirdumisega isoleeris Ehnaton end väga olulisel määral tegelikkusest, sest eelmise vaarao sugulased, vana õukonna võimukad liikmed ja kompetentsed ametnikud, kelle võimu Ehnaton otsustavalt väärata ei suutnud, valitsesid Egiptust reaalselt edasi mõlemast vanast pealinnast. Riik pidi ju toimima.

Kuhugi ei kadunud ka peajumal Amoni ega teiste jumalate kultus. Amoni preestrid, kes tahtsid säilitada oma juhtpositsiooni maa religioosses elus, tegid Atoni-vastast kihutustööd. Enamik lihtrahvast kummardas endiselt edasi vanu jumalaid, sest Atoni müstitsismi kalduv teoloogia oli talupoegadele ja linnakehvistule lihtsalt arusaamatu.

Võib arvata, et Atoni ideaalriik eksisteeris tegelikkuses vaid Ahet-Atoni kitsal territooriumil. Vaarao eest varjati ebameeldivaid tõsisasju, ta oli riigi tegelikust olukorrast halvasti informeeritud (vt nt Jacq 2000: 178). Maksud laekusid ebaregulaarselt, süvenev majanduslik laos riigis (Jacq 2000: 182) viis kohati boikottide ja lokaalsete mässudeni, mida vaarao püüdis maha suruda põhiliselt võõramaalastest palgasõdurite abiga (Stadnikov 1998a: 319).

Välispoliitiliselt tabas Egiptuse impeeriumi katastroof. Nagu ilmneb Amarna varemetest leitud rikkalikust kiilkirjalisest kirjavahetusest allutatud piirkondade halduritega ja teiste valitsejatega (vt Moran 1997), kaotas Egiptus mõjuvõimu peaaegu kõikide territooriumite üle Süürias ja Palestiinas, mis varem olid olnud vasallisõltuvuses Egiptusest. Selle põhjuseks oli nii vaarao hõivatus sisepoliitiliste probleemidega kui ka hetiitide algatatud mässud. Egiptuse välispoliitiline hiilgus suudeti mingil määral taastada alles XIX dünastia ajal.

Sise- ja välispoliitilisi ebaõnnestumisi kroonisid vajakajäämised vaarao eraelus. Nofretete sünnitas Ehnatonile kuus tütart, kes nähtavasti ei olnud füüsiliselt või vaimselt täisväärtuslikud ja kellest kõik ei elanud täiealiseks saamiseni. Vaarao viimastel valitsusaastatel kaob kuninganna Nofretete annaalidest, nähtavasti langes ta ebasoosingusse ja suri noorelt. Viimasel kolmel eluaastal valitses Ehnaton koos oma väimehe Semenhkaraga, kellel õnnestus saavutada kompromiss Amoni preesterkonnaga. Seda nn restauratsioonipe- 
rioodi võib pidada religioosse kaksikvõimu ajajärguks. Ehnatoni surmale järgnenud valitsejate Eje, Tutanhamoni ja Horemhebi ajal vajus Atoni kultus ajapikku unustusse ja vana usund taastati suhteliselt rahumeelselt. Ehnatoni mälestuse ja temaga seotud mälestusmärkide süstemaatiline hävitamine algas alles XIX dünastia vaaraode Seti I ja Ramses II ajal (Jacq 2000: 210).

Ehnatoni nn revolutsioon kukkus läbi, sest ta püüdis väevõimuga läbi suruda religioosseid ideid, mis jäid rahvale arusaamatuks kas või seetõttu, et puudus üldrahvalik kultus ja huvipakkuv mütoloogia, samuti seetõttu, et uus usund püüdis juurutada mitte-osirislikku hauataguse elu kontseptsiooni ja teha lõppu harjumuspärastele matusetavadele (David 2005: 229-230). Atoni religioon ei leidnud poliitilistel ja majanduslikel põhjustel ka ülemkihtide poolehoidu.

Universalistlikke tendentse väljendavat religioosset ideoloogiat ja nende ideede realiseerimise taotlusi tunneb ju kogu Vana-Egiptuse riikluse pikk ajalugu (vt selle kohta koos vastava ulatusliku kirjandusega Stadnikov 1998b: 93-142). Ehnaton pole siin erand. Ent vaatamata radikaalsetele ja otsustavatele abinõudele ei olnud tema katsel edu, sest monoteismi idee oli egiptlastele võõras. On avaldatud arvamust (Hornung 1983: 191jj), et traditsiooniliselt polüteistlikud egiptlased ei suutnud jumala ühesust ning seetõttu ka monoteismi ette kujutada ning monoteismi juurutamine tähendas ühtlasi fundamentaalset loogikamuutust. Oma sammuga muutis Ehnaton traditsioonilisi uskumusi liiga kardinaalselt. Võib-olla oleks ettevõtmisel olnud rohkem edu, kui usureformi oleks läbi viidud järk-järgult ja Aton oleks esialgu ülendatud üheks henoteistlikuks peajumalaks teiste kõrval.

Ehnatoni üks motiive olid kindlasti tema religioossed arusaamad ja mingil määral oli ta ka idealist, mida näitab kas või tema eraldumine Ahet-Atonisse oma "Atoni kuningriiki", pealegi polnud ei Atoni teoloogias ega Ehnatoni religioosses maailmapildis (mis oli ju iseenesest üks ja seesama!) kohta reaalse elu varjukülgedele (Stadnikov 1998a: 319). Teiselt poolt ei tohi alahinnata tema soovi saavutada poliitilist ainuvõimu, elimineerides selleks mõjukad poliitilised grupeeringud (Amoni preesterkond, vana aristokraatia ja korrumpeerunud kõrgametnikkond), samuti piisas tal otsustavust rakendada repressiivabinõusid, mille toel suutis ta niigi kaua valitseda. Siit nähtub, et uurijatel, kes on püüdnud näidata, et Ehnaton kasutas Atoni kultust Amon-Ra preesterkonna allasurumiseks ja kuningavõimu ülimuslikkuse taastamiseks, võib olla olulisel määral õigus (nt Redford 1984). 


\section{Analüüs}

Vaadelgem nüüd Amenhotep IV valitsemisaja poliitilist situatsiooni siinkirjutaja poolt varem välja pakutud nn varatotalitaarse riigi kontseptsiooni kontekstis. Esmalt kasutas siinkirjutaja seda kontseptsiooni muistse Peruu inkade Tahuantisuyu riigikorra puhul (Kulmar 2002; vt ka Kulmar 2003/2005), ${ }^{4}$ hiljem ka Vana-Hiina Qini keisririigi valitsemissüsteemi määratlemisel (Kulmar 2007).

Kõnesoleva kontseptsiooni järgi võib varatotalitaarse riigi puhul eristada järgmisi põhifaktoreid (Kulmar 2002: 40-42):

süsteemi ajaloolis-poliitilised tekke- ja hävingupõhjused, administratsioon ja haldus,

majandus,

sotsiaalelu,

õiguskord,

ideoloogia,

välispoliitika.

Nendel faktoritel on rida tunnuseid, mida käsitleme järgneva analüüsi käigus. Kui mingi riigikord või valitsemissüsteem vastab kõikidele allpool toodud tunnusjoontele, on tegemist varatotalitaarse riigi ideaaljuhtumiga, nagu Tahuantinsuyu ja Qini impeeriumid seda ka väga suure tõenäosusega olid. Mida vähematele esitatud tunnusjoontele mingi valitsemissüsteem vastab, seda väiksem on selle totalitaarsuse võimalik aste. Loomulikult, mida rohkem on vastava kaasuse kohta informatsiooni, seda tõenäolisemalt vastab hinnang tõele.

Kuidas vastab varatotalitaarse riigi tunnustele Ehnatoni riigikord selle meile teadaoleva (paraku suhteliselt kasina) informatsiooni põhjal, mille põhilised jooned on ülal esitatud?

\section{Süsteemi ajaloolis-poliitilised tekkimise ja hävimise põhjused}

Sise- või välispoliitilise kriisisituatsiooni olemasolu; süsteemi loomine subjektiivsel teel (riigivalitseja isiku keskselt) objektiivseid ohutegureid ära kasutades; suhteliselt lühiajaline kestvus; süsteemi hävimine kas seesmise kriisiolukorra tõttu või välisjõu survel.

Amenhotep III pärandas pojale õitsva riigi. Ometi pole võimatu, et Ehnaton tunnetas erinevaid surveid, mida pidas kuningavõimule ohtlikeks: poliitilist survestatust preesterkonna poolt ja majanduslikku survestatust (ilmselt) korrumpeerunud ametnikkonna poolt. Reformide algataja ja läbiviija oli vaarao Ehnaton ise, asudes kahandama preestrite ja vana õukonna mõjuvõimu. Re- 
formid kestsid vaid kümmekond aastat. Süsteem hävis, kuna tekkis ulatuslik vastuseis ja revolutsioon "ülalt" kukkus läbi. Kokkuvõttes vastab Ehnatoni kaasus kõigiti selle faktori tunnusjoontele.

\section{Administratsioon ja haldus}

Rahvast isoleerunud võimueliit; rangelt tsentraliseeritud keskvõim; ametnikkonna äärmuslik bürokratiseerumine; võimalikult suur kontroll informatsiooni leviku ja tarbimise üle.

Võib arvata, et Ahet-Atonisse eraldunud vaarao ei olnud täiel määral kursis tegelikku olukorraga, eriti ebaõnnestumistega oma reformide elluviimisel. Samas puutus vaarao kokku lihtrahvaga Atoni kultuse avalikel talitustel. Keskvõim ei saanud toimida efektiivselt, sest sisuliselt kehtis ju erinevates pealinnades valitsenud vana ja uue õukonna kaksikvõim. Ei ole põhjust pidada Ehnatoni ametnikkonda rohkem bürokratiseerunuks kui Amenhotep III ajal - pigem püüdis Ehnaton kahandada vana ametnikkonna mõjuvõimu. Oletatavasti esines informatsiooni leviku kontrollimisel mitu vastandlikku suundumust: vaarao püüdis rahvale näidata, et Atoni kultus on populaarne ja edukas, preestrid ja vanameelsed ametnikud püüdsid varjata Ahet-Atoni õukonna eest vaarao käskude boikoteerimist, Ahet-Atoni õukond jällegi püüdis varjata vaarao eest tegelikku olukorda. Majandusliku olukorra halvenedes võis mingil määral kõne alla tulla toiduainete tarbimise reglementeerimist, kuigi selle kohta puuduvad andmed. Kokkuvõttes kehtivad selle faktori tunnused Ehnatoni kaasuse puhul osaliselt ja tinglikult.

\section{Majandus}

Riikliku omandi domineerimine eraomandi suhtes või eraomandi puudumine; suund võimalikult autarkilisele majandusele; tootmise ja tarbimise keskne ja jäik planeerimine ja kontroll; üleüldine töökohustus; kunstlikult kehtestatud turusuhted; riikliku sunduse rakendamine suurprojektide elluviimisel.

Egiptuses esines mitut liiki omandit, kuid domineerisid just eraomandi erinevad vormid. Paljud varajased majandused, Egiptuses kaasa arvatud, olid loomult üsna autarkilised, väliskaubanduse roll oli suhteliselt väike ja see puudutas põhiliselt mitteesmatarbekaupu. Ei ole teada, et Ehnaton oleks püüdnud kehtestada midagi plaanimajanduse sarnast. Üleüldist sunduslikku töökohustust ei eksisteerinud, kuigi seda võis ajuti pealinna ehitamisel ette tulla. Mässudest põhjustatud majandusliku laose süvenedes võidi perioodi lõpupoole püüda toiduaineid normeerida, kuid see on vaid oletus. Kuigi kogu Egiptuse ajaloos rakendati töömahukate rajatiste ehitamiseks sunniviisiliselt suuri inim- 
hulki, ilmneb Ehnatoni puhul see tendents Atoni templite, eriti aga uue pealinna Ahet-Atoni kiiretempolisel rajamisel. Järelikult sobivad selle faktori tunnused Ehnatoni kaasusega vähesel määral.

\section{Sotsiaalelu}

Suund elukorralduse reglementeerimisele riiklike plaani-ja kontrollimehhanismide abil; liikumisvabaduse ja muude isikuvabaduste piiramisele; segregatsioon teatud ühiskonnakihtide suhtes; teatud ühiskonnarühmade assimileerimine; vähemuste süstemaatiline allasurumine kuni hävitamiseni; riiklik demograafiline kontroll.

Ei ole teada, et Ehnaton oleks püüdnud sekkuda töötava rahva traditsioonilisse elukorraldusse või piirata liikumisvabadust või muid seisuseomaseid vabadusi. Kui kedagi diskrimineeriti, siis need olid kindlasti Amon-Ra kultuse avalikud pooldajad ja reformidele vastutöötajad, keda ei olnud arvatavasti vähe. Pole mingeid andmeid vähemuste terroriseerimisest, pigem vastupidi, sest Ehnaton kuulutas Atoni teoloogia kohaselt etnilist ja keelelist samaväärsust. Teadaolevalt ei kehtestatud Egiptuses mingeid iibekontrollimehhanisme. Kokkuvõttes kehtivad selle faktori tunnused Ehnatoni kaasuse puhul vaid vähesel määral.

\section{5. Õiguskord}

Seadusanduse toimimine põhimõttel "see, mis ei ole lubatud, on keelatud"; julmad karistused; ühisvastutuse domineerimine isikuvastutuse ees; teisitimõtlemise jälitamine; repressivivaparaadi olemasolu.

Egiptuse õiguskorraldus ega seadused ei teinud Ehnatoni ajal teadaolevalt läbi olulisi muutusi rangemaks muutumise suunas. Pole andmeid, et üksikisiku õigusrikkumise eest oleks kogukondade suhtes senisest rohkem rakendatud ühisvastutust. Küll aga laskis vaarao eriliselt jälgida, kuidas täidetakse tema korraldusi, mis puudutasid ametnikkonna väljavahetamist, Amoni preestrite mõjuvõimu vähendamist ning Atoni kultuse juurutamist ja vanade jumalate kultusest loobumist. Selle jälgimiseks ja eksinute karistamiseks oli olemas vastav aparaat. Järelikult kehtivad selle faktori tunnused Ehnatoni kaasuse puhul osaliselt.

\section{Ideoloogia}

Süsteemi aluseks olev filosoofia või religioon on muudetud spetsiaalse propagandaaparaadi poolt ametlikuks riigiusundiks; mütologiseeritud isikukultus; eesmärgipärased massitseremooniad; doktrineeritud etnotsentrism; eesmärgipäraselt suunatud haridus-ja kultuuripoliitika; ava- 
liku teabe ja ajalookäsituse tsenseerimine mõtlemise unifitseerimise eesmärgil.

Ehnatoni reformide aluseks oli tema poolt loodud ainujumala Atoni kultus, mis omandas riigiideoloogia staatuse. Seda propageeris ja juurutas selleks loodud Atoni preesterkond. Atoni kultus samastus riigi tasemel vaarao Ehnatoni isikukultusega. Atoni ja vaarao auks toimetati avalikke riitusi, millest võtsid osa suured rahvahulgad. Etnotsentrismist antud ajastul küll rääkida ei saa. Egiptlastele oli üldse võooras dogmaatiline ksenofoobia, eriti avarad võimalused avanesid võõramaalastele Uue riigi perioodil (Stadnikov 1998: 23), Ehnaton jutlustas aga koguni kõikide inimeste samaväärsust Atoni ees. Atoni õpetuse levitamisega laskis vaarao tegelda süstemaatiliselt. Informatsiooni ja ajaloo tsenseerimise poolt räägivad sammud, mis võeti ette selleks, et Amoni ja mingil määral teiste kultus unustusse vajuks. Järelikult vastab Ehnatoni kaasus, üks erand välja arvatud, üsna täielikult selle faktori tunnustele.

\section{Välispoliitika}

Poliitilise hegemoonia taotlemine naaberterritooriumide suhtes; kestev valmistumine agressiooniks ja pidev valmisolek agressiooni ellu viia; riigi välispoliitika süstemaatiline teostamine jõupositsioonilt ja sõjaliste vahenditega.

Need tunnused on mõne erandiga tegelikult omased kogu Egiptuse Uue riigi välispoliitikale, ent erandite seas on ka Ehnatoni valitsusaeg. Võiks isegi väita, et välispoliitika oli Ehnatoni valitsemise kõige edutum valdkond, mille põhjuseks oli vaarao halb informeeritus ja kestev hõivatus siseasjadega. Seega Ehnatoni kaasus selle faktori tunnustele ei vasta.

\section{Järeldused}

Ülaltoodust nähtub, et täielikult või peaaegu täielikult vastab Ehnatoni valitsemisviis varatotalitaarse riigi tunnustele ainult ajaloolis-poliitiliste põhjuste ja ideoloogia faktorite osas. Osaliselt kehtib see administratsiooni ja õiguskorra osas. Vähesel määral võib Ehnatoni valitsemisajast leida varatotalitaarsuse tunnuseid majanduse ja sotsiaalelu vallas. Vaid välispoliitika faktor ei näita Ehnatoni valitsemisviisi puhul varatotalitaarsuse tunnuseid.

Kokkuvõttes saab küllalt suure tõenäosusega järeldada, et vaarao Amenhotep IV alias Ehnaton oli teel varatotalitaarse riigivalitsemisviisi poole. Selleks olid olemas ajaloolispoliitilised tingimused, tal oli sobiv ideoloogia, mida ta jõuliselt propageeris, ja ta oli jõudnud küllalt kaugele vastava haldus- ja õiguskorra loomisel. Majandus- ja sotsiaalkorraldus on aga sellised riigielu 
valdkonnad, mille kardinaalsemaks muutmiseks on tarvis aega. Just seda Ehnatonil ei olnud - tema ulatuslikum reformitegevus kestis vaid veidi rohkem kui kümmekond aastat.

Niisiis on võimalik, et Ehnatoni eksperiment oli üks varaseimaid teadaolevaid varatotalitaarse riigi loomise katseid inimkonna ajaloos.

\section{Kommentaarid}

1 Artikkel on seotud Eesti Teadusfondi grandiga nr. 6626.

2 Daatumid tuginevad teosele Clayton 2001: 120.

${ }^{3}$ Ka 1364-1347 eKr (vt Stadnikov 1998: 313) või 1379-1362 eKr (vt David 2005: 359).

4 Siinkirjutaja esitas kõnealuse kontseptsiooni süstematiseeritud kujul esmakordselt 2002. aastal saksa keeles. Publikatsioon, mis kannab aastanumbrit 2003 ja ilmus tegelikult 2005, on eelmise mõnevõrra muudetud ingliskeelne versioon (vt tekstis olevat viidet).

\section{Kirjandus}

Assmann, Jan 1975. Ägyptische Hymnen und Gebete. Zürich: Artemis \& München: Müller.

Assmann, Jan 1984. Ägypten: Theologie und Frommigkeit einer frühen Hochkultur. Stuttgart: Kohlhammer.

Clayton, Peter A. 2001. Vaaraode kroonika. Vana-Egiptuse valitsejad ja dünastiad valitsemisaegade kaupa. Tallinn: Eesti Entsüklopeediakirjastus.

David, Rosalie 2005. Religioon ja maagia Vana-Egiptuses. Tallinn: Tänapäev.

Doherty, Paul 2004. Tutanhamon. Vaarao mõistatuslik surm. Tallinn: Kunst.

Grimal, Nicolas A. 1992. History of Ancient Egypt. Oxford-Cambridge (Mass.): Oxford University Press.

Hornung, Erik 1978. Grundzüge der ägyptischen Geschichte. Darmstadt: Wissenschaftliche Buchgesellschaft.

Hornung, Erik 1983. Conceptions of God in Ancient Egypt: The One and the Many. London: Melbourne and Henly.

Jacq, Christian 2000. Nofretete ja Ehnaton. Tallinn: Kunst.

Kulmar, Tarmo 2002. Die Totalität des Inkareiches und die Rolle der Religion. Trames 1: 6 (56/51). Tallinn, lk 38-49.

Kulmar, Tarmo 2003/2005. Totalitarianism and the Role of Religion in the Inca State. Folklore. Electronic Journal of Folklore 23, lk 25-39 (http://www.folklore.ee/vol23/ incastate.pdf - 28. juuni 2009).

Kulmar, Tarmo 2007. Vana-Hiina Qini keisririigi valitsemissüsteemi olemusest. Mäetagused. Hüperajakiri 35, lk 141-154 (http://www.folklore.ee/tagused/nr35/kulmar.pdf - 28. juuni 2009). 
Lichtheim, Miriam 1976. Ancient Egyptian Literature 2. University of California Press. Moran, William L. (toim) 1997. The Amarna Letters. John Hopkins University Press. Morenz, Siegfried 1984. Gott und Mensch im alten Ägypten. Leipzig: Koehler \& Amelang. Murnane, William J. 1995. Texts from the Amarna Period in Egipt. Atlanta (Georgia): Scholars Press.

Redford, Donald B. 1984. Akhenaten. The Heretic King. Princeton: Princeton University Press.

Shafer, Byron E. (toim) 1997. Temples of Ancient Egypt. Ithaca: Cornell University Press.

Stadnikov, Sergei 1998a. Igavesest ja kaduvast M. Waltari ajaloovisioonis ning selle egüptoloogilisest taustast. Stadnikov, Sergei. Vana-Egiptuse kultuurilugu. Valitud artikleid, tõlkeid ja esseid. Tallinn: Kodutrükk, lk 301-322.

Stadnikov, Sergei 1998b. Universalism kui fenomen. Universalistlikud tendentsid Egiptuse kuningate ideoloogias. Stadnikov, Sergei. Vana-Egiptuse kultuurilugu. Valitud artikleid, tõlkeid ja esseid. Tallinn: Kodutrükk, lk 93-142.

\section{Summary}

\section{On a Possible Characteristic of the Governing System of Pharaoh Amenhotep IV (Akhenaten)}

Tarmo Kulmar

Key words: Amenhotep IV (Akhenaten), earliest totalitarianism, ideology, monotheism, New Kingdom of Ancient Egypt, religion, state power

The article explores the relationship between the religious reform of Pharaoh Amenhotep IV (Akhenaten) of the New Kingdom of Ancient Egypt and changes in the government system. The analysis, which is based on historical data and relies on the diagram of the concept of the early totalitarian state by the author, reveals that Akhenaten's governing system (almost) entirely corresponds to that of an early totalitarian state in terms of historical-political causes and factors of ideology, partly in terms of administrative and legislative system, and only few features of early totalitarianism could be found in the economy and the social order. Akhenaten's foreign politics reveal no features of early totalitarianism. It can be concluded, quite confidently, that Pharaoh Amenhotep IV (Akhenaten) was moving towards the early totalitarian rule of government and it is possible that Akhenaten's experiment was one of the first known attempts to create an early totalitarian state in the history of mankind. 